\title{
Modulation of Microglial Process Convergence Toward Neuronal Dendrites by Extracellular Calcium
}

\author{
OUkpong B. Eyo, ${ }^{1}$ Nan Gu, ${ }^{1,2}$ Srijisnu De, ${ }^{1}$ Hailong Dong, ${ }^{2}$ Jason R. Richardson, ${ }^{3}$ and Long-Jun $\mathrm{Wu}^{1,4}$ \\ ${ }^{1}$ Department of Cell Biology and Neuroscience, Rutgers University, Piscataway, New Jersey 08854, ${ }^{2}$ Department of Anesthesia, the Fourth Military Medical \\ University Xijing Hospital, Xi' an, China, 710032, ${ }^{3}$ Department of Environmental and Occupational Medicine, Rutgers University Robert Wood Johnson \\ Medical School, Piscataway, New Jersey 08854, and ${ }^{2}$ Department of Physiology, School of Basic Medical Sciences, Anhui Medical University, Hefei, China, \\ 230032
}

Extracellular calcium concentrations in the brain fluctuate during neuronal activities and may affect the behavior of brain cells. Microglia are highly dynamic immune cells of the brain. However, the effects of extracellular calcium concentrations on microglial dynamics have not been investigated. Here, we addressed this question in mouse brain slices and in vivo using two-photon microscopy. We serendipitously found that extracellular calcium reduction induced microglial processes to converge at distinct sites, a phenomenon we termed microglial process convergence (MPCs). Our studies revealed that MPCs target neuronal dendrites independent of neuronal action potential firing and is mediated by ATP release and microglial P2Y12 receptors. These results indicate that microglia monitor and interact with neurons during conditions of cerebral calcium reduction in the normal and diseased brain.

Key words: calcium reduction; microglia; microglial process convergence; neuronal dendrites; P2Y12 receptor

\section{Introduction}

Microglia are the principal resident immune cells of the CNS actively involved in the developmental pruning of synapses (Paolicelli et al., 2011; Schafer et al., 2012), clearance of apoptotic neurons (Marín-Teva et al., 2004; Wakselman et al., 2008), enhancement of neuronal survival (Ueno et al., 2013), and regulation of synaptic function (Pascual et al., 2012; Eyo and Wu, 2013; Ji et al., 2013; Parkhurst et al., 2013). Moreover, mounting evidence indicates physiologically relevant physical interactions between microglia and neurons (Wake et al., 2009; Tremblay et al., 2010; Li et al., 2012). We recently showed that neuronal hyperactivities induced microglial interaction with neuronal somata and dendrites (Eyo et al., 2014). However, factors regulating such interactions have not been elucidated.

Calcium ions are required for various biological processes (Berridge et al., 2000; Clapham, 2007) and are important for neuronal activity such as synaptic plasticity (Cavazzini et al., 2005) and glial functions including gliotransmitter release (Zorec et al., 2012). The intracellular calcium concentration is maintained at $\sim 100 \mathrm{nM}$, whereas that in the extracellular CSF is main-

\footnotetext{
Received Aug. 7, 2014; revised Dec. 10, 2014; accepted Dec. 20, 2014.

Author contributions: U.B.E., J.R.R., and L.-J.W. designed research; U.B.E., N.G., and S.D. performed research; H.D., J.R.R., and L.-J.W. contributed unpublished reagents/analytic tools; U.B.E. analyzed data; U.B.E. and L.-J.W. wrote the paper.

This work was supported by National Institute of Health (R01NS088627, P30ES005022, T32ES007148, and R01ES021800), American Heart Association (11SDG7340011), and Michael J. Fox Foundation. We thank Dr Michael E. Dailey (University of lowa) for providing us with P2Y12 knock-out mice.

The authors declare no competing financial interests.

Correspondence should be addressed to Dr Long-Jun Wu, Department of Cell Biology and Neuroscience, Rutgers University, 604 Allison Road, Piscataway, NJ 08854. E-mail: Iwu@dls.rutgers.edu.

DOI:10.1523/JNEUROSCI.3279-14.2015

Copyright $\odot 2015$ the authors $\quad 0270-6474 / 15 / 352417-06 \$ 15.00 / 0$
}

tained at $\sim 2 \mathrm{~mm}$ (Clapham, 2007). This $\sim 20,000$-fold gradient between compartments is established because $\mathrm{Ca}^{2+}$ is a major mediator of cell signaling. Extracellular calcium concentrations $\left(\left[\mathrm{Ca}^{2+}\right]_{\mathrm{e}}\right)$ can decrease significantly during periods of intense neuronal activity, such as during seizures (Heinemann et al., 1986 ), as well as during ischemia when $\left[\mathrm{Ca}^{2+}\right]_{\mathrm{e}}$ can drop to $\sim 0.1$ mM (Kristián and Siesjö, 1998). However, microglial responses to such decreases in $\left[\mathrm{Ca}^{2+}\right]_{\mathrm{e}}$ are unknown.

To address this question, we performed high resolution twophoton cellular imaging in slices and in vivo. We serendipitously found a novel microglial behavior in sensing changes in neuronal physiology triggered by $\left[\mathrm{Ca}^{2+}\right]_{\mathrm{e}}$ reduction that may be relevant during synaptic physiology and pathology.

\section{Materials and Methods}

Animals. Animals were used in accordance with institutional guidelines as approved by the animal care and use committee at Rutgers University. Heterozygous (CX3CR $1^{\mathrm{GFP} /+}$ ) and double-transgenic GFP-YFP $\left(\mathrm{CX} 3 \mathrm{CR} 1^{\mathrm{GFP} /+}\right.$; Thy $1^{\mathrm{YFP} /+}$ ) reporter mice were used (Feng et al., 2000; Jung et al., 2000). P2Y12 knock-out mice were obtained from Dr Michael Dailey (University of Iowa).

Slice and in vivo preparation and two-photon imaging. Slices were prepared from 3- to 5-week-old mice of either sex as described previously (Wu et al., 2012; Eyo et al., 2014). For two-photon cellular imaging, 15 consecutive $z$-stack images were collected at $3 \mu \mathrm{m}$ intervals every $1-2$ min for slices or $1.5 \mu \mathrm{m}$ intervals every $1-2 \mathrm{~min}$ for in vivo imaging between 50 and $100 \mu \mathrm{m}$ from the slice and in vivo cortical surface. For two-photon calcium imaging, astrocytes in hippocampal slices were labeled with Oregon Green Bapta-AM (OGB, $0.5 \mathrm{~mm}$ ) and sulforhodamine $101(\mathrm{SR} 101,5 \mu \mathrm{M})$ through an injection pipette in the stratum radiatum. Images were taken at $15 \mathrm{~s}$ intervals for $30 \mathrm{~min}$ before and after $10 \mathrm{~mm}$ fluoroacetate (FAC). Imaging was done at $900 \mathrm{~nm}$ (for GFP microglia, YFP neurons and SR101 astrocytes) or $800 \mathrm{~nm}$ (for OGB) with a $40 \times$ 


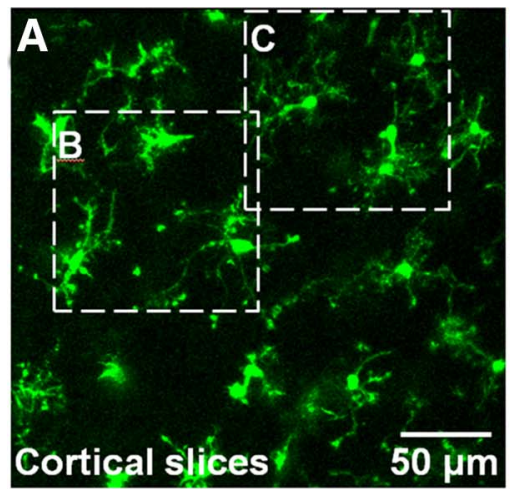

D

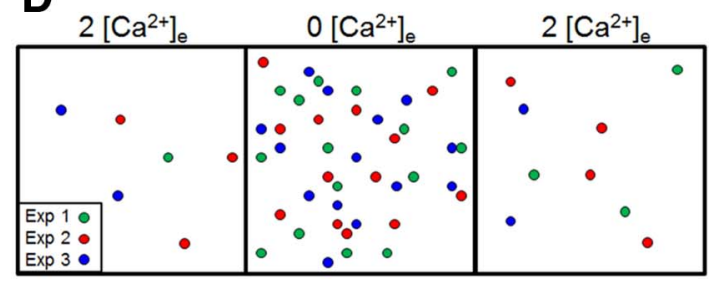

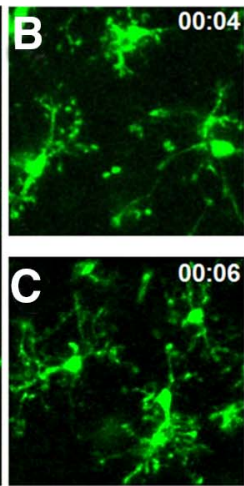
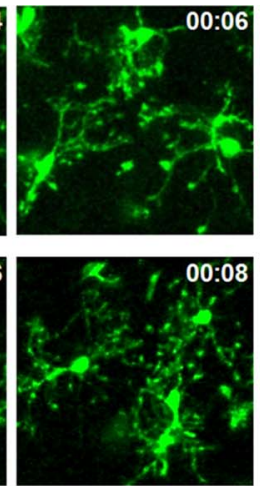

E

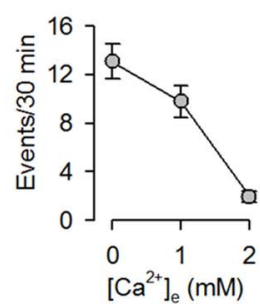

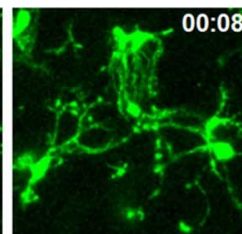
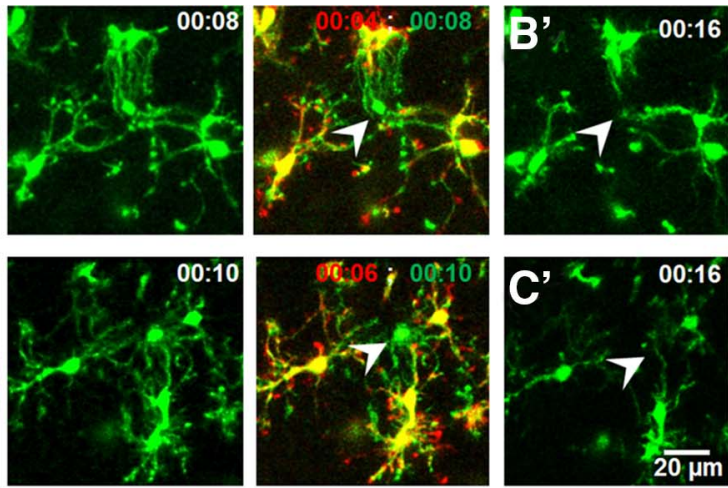

$\mathbf{F}$

G
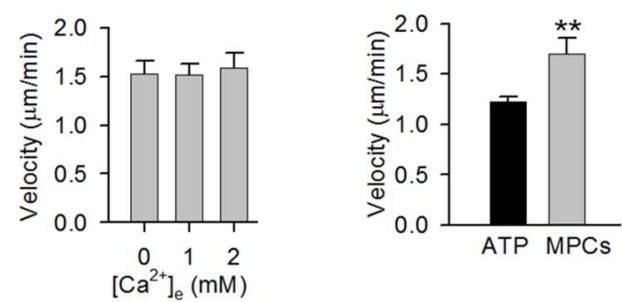

Figure 1. Extracellular calcium reduction induces microglial process convergence in brain slices. $\boldsymbol{A}$, Low-magnification two-photon z-stack image of GFP-expressing microglia in layer II/III of a cortical brain slice. $\boldsymbol{B}, \boldsymbol{C}$, Representative higher-magnification time-lapse images from boxed regions in $(\boldsymbol{A})$ showing converging microglial processes during nominally free calcium conditions. Right most images are color-coded images before (red) and after (green) the process convergence where the focal points are indicated with white arrowheads. $\boldsymbol{B}^{\prime}-\boldsymbol{C}^{\prime}$, Images following the collapse of the converging microglial processes in $\boldsymbol{B}, \boldsymbol{C}$. D, Schematic of representative calcium switch experiments showing the location of convergent foci in the field-of-view. $\boldsymbol{E}$, Quantitative data showing microglial process convergence in different extracellular calcium concentrations ([C $\left.\left.\mathrm{a}^{2+}\right]_{\mathrm{e}}\right) ; n=30$ slices at $0 \mathrm{~mm}, 19$ slices at $1 \mathrm{~mm}$ and 27 slices at 2 mm. $\boldsymbol{F}$, Velocity of extending processes during different calcium concentrations. $\mathbf{G}$, Velocity of converging microglial processes during endogenous process convergence and exogenous ATP application through a pipette; ${ }^{* *} p<0.01$.

water-immersion lens (0.8 NA; Olympus). For in vivo imaging, a craniotomy was made in the somatosensory cortex of 1- to 2-month-old mice.

Drugs. Sulforhodamine 101 (SR101), ATP, Brilliant Blue G (BBG), carbenoxolone (CBX), probenecid (PB), and sodium FAC were purchased from Sigma-Aldrich. TTX was purchased from Tocris Bioscience. OGB was from Invitrogen.

Statistical analysis. Quantification of microglial process convergence (MPC) events was done manually from $330 \times 330 \times 45 \mu \mathrm{m}$ fields-ofview for $30 \mathrm{~min}$ in slices and $220 \times 220 \times 45 \mu \mathrm{m}$ fields-of-view for $1 \mathrm{~h} \mathrm{in}$ vivo. Data are presented as mean \pm SEM. Student's $t$ test or one-way ANOVA with Bonferroni corrections were used to establish significance.

\section{Results}

\section{Extracellular calcium reduction induces microglial} process convergence

We performed switch experiments from ACSF media containing $2 \mathrm{mM} \mathrm{Ca}^{2+}$ to nominally calcium-free media in acute brain slices which induced a novel phenomenon, which we termed MPCs. Here, several microglial processes from 1 to 4 microglia spontaneously extended their processes toward a central focal point transiently for several minutes after which they collapse (Fig. $1 A-C$; Movie 1). In addition, MPCs are reversible as the number of MPCs is reduced upon return from nominally calcium-free conditions to normal calcium conditions (Fig. 1D). MPCs are strictly dependent on extracellular calcium concentrations $\left(\left[\mathrm{Ca}^{2+}\right]_{\mathrm{e}}\right)$ : MPCs occurs at a high-frequency under nominally free $\left[\mathrm{Ca}^{2+}\right]_{\mathrm{e}}$ conditions $(13.1 \pm 2.4$ events per $30 \mathrm{~min})$ and $1 \mathrm{~mm}$ $\mathrm{Ca}^{2+}(9.8 \pm 1.3$ events per $30 \mathrm{~min})$, but not at $2 \mathrm{mM} \mathrm{Ca}^{2+}(2.0 \pm$ 0.5 events per $30 \mathrm{~min}$; Fig. $1 E$ ). Interestingly, these events displayed similar velocities toward the focal point under all $\left[\mathrm{Ca}^{2+}\right]_{\mathrm{e}}$ conditions tested (Fig. 1F). MPCs are reminiscent of microglial chemotaxis to a point source of ATP (Wu et al., 2007). However, microglial processes extended much faster during MPCs than during exogenous ATP application $(1.7 \pm 0.15$ vs $1.2 \pm 0.05$

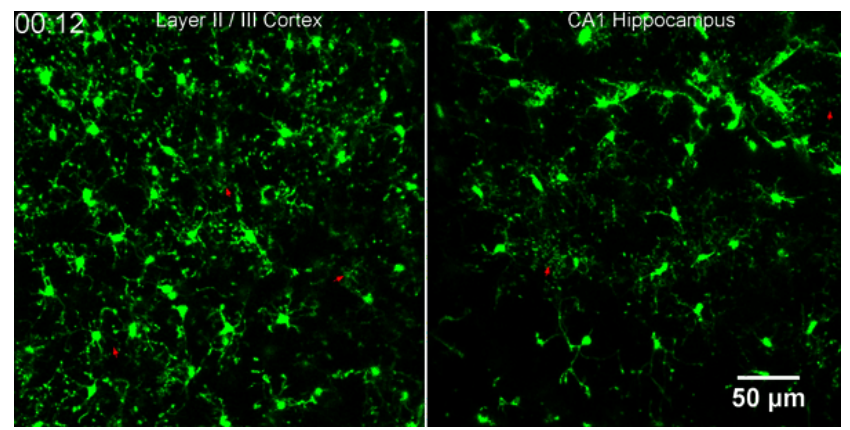

Movie 1. Calcium reduction induces microglial process convergence in brain slices. Timelapse movie of microglial process convergence during calcium reduction in acute cortical (left) and hippocampal (right) brain slices. MPCs are identified with red arrows. The movie is $30 \mathrm{~min}$ long.

$\mu \mathrm{m} / \mathrm{min}$; Fig. $1 G)$. MPCs are pan-cerebral phenomena, as they are observed in all brain regions tested including cortical, hippocampal, striatal, and amygdala slices (data not shown).

We set out to determine whether MPCs occur in the intact brain by performing in vivo two-photon imaging and monitoring microglial dynamics under basal conditions followed by reducing $\left[\mathrm{Ca}^{2+}\right]_{\mathrm{e}}$. Topical application of nominally calcium-free ACSF with 2 mM EGTA to an open craniotomy dramatically increased MPC frequency from $0.6 \pm 0.3$ to $9.5 \pm 0.8$ events per hour which was also reversible (Fig. $2 A-D$ ). The delay to the initiation of MPCs in slices and in vivo were $8.7 \pm 0.6 \mathrm{~min}$ (range, 6-14 min; $n=10$ slices) and $19.4 \pm 4.1$ (range, $10-35 \mathrm{~min} ; n=5$ mice), respectively. Under control conditions, only $12.7 \pm 1.1 \%$ (range, $8-20 \% ; n=10$ slices) and $2.9 \pm 1.5 \%$ (range, $0-7 \% ; n=4$ mice) of microglia underwent MPCs in 30 min imaging sessions in slices and $60 \mathrm{~min}$ imaging sessions in vivo, respectively. This in- 

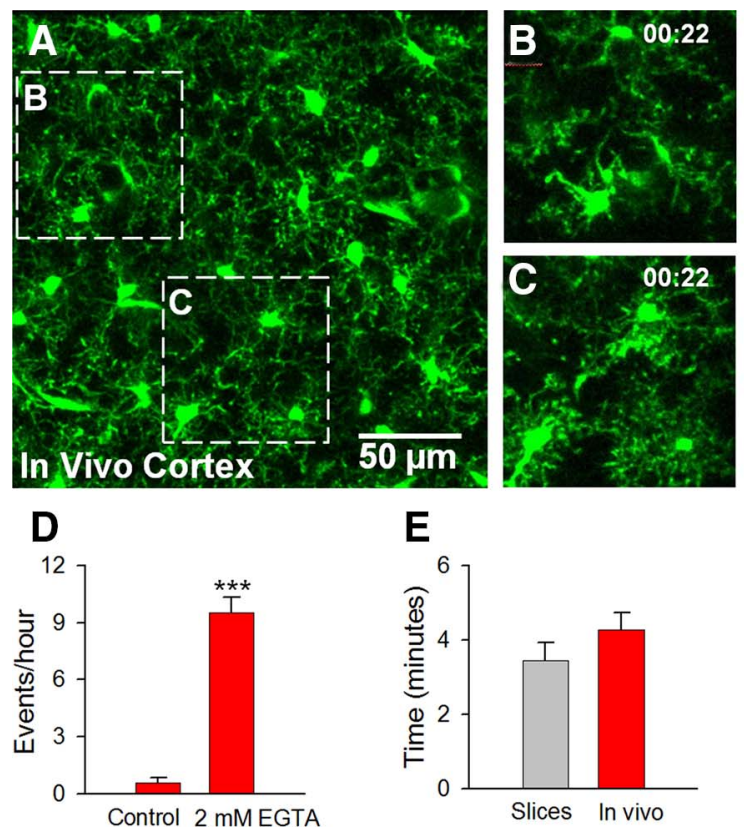
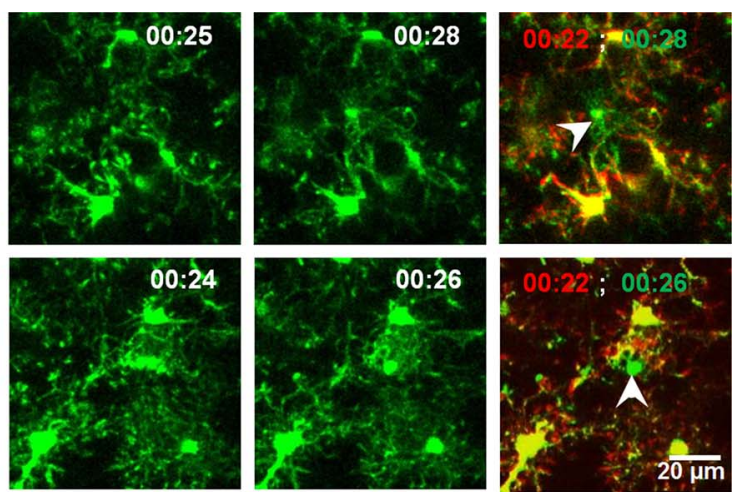

$\mathbf{F}$

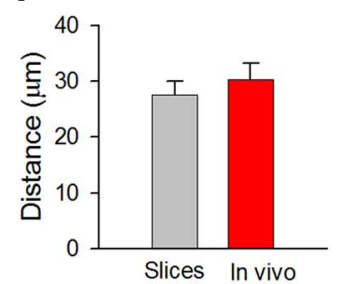

G

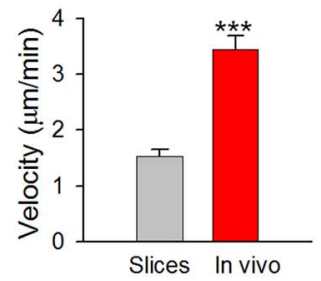

Figure 2. Microglial process convergence in vivo. $\boldsymbol{A}$, Low-magnification two-photon z-stack image of GFP-expressing microglia in the intact cortex in vivo. $\boldsymbol{B}$, $\boldsymbol{C}$, Representative highermagnification time lapse images from boxed regions in $\boldsymbol{A}$ showing converging microglial processes during calcium reduction induced by topical application of 2 mm EGTA. Rightmost images are color-coded images before (red) and after (green) the process convergence where the focal points are indicated with white arrowheads. $\boldsymbol{D}$, Quantitative data showing process convergent events during calcium reduction in vivo ( $n=8$ mice under control and 4 mice under calcium-reduction conditions). $\boldsymbol{E}-\mathbf{G}$, Quantitative data showing responses between microglia in slices and in vivo during calcium reduction with respect to the duration of contact $(\boldsymbol{E})$, the maximal distance from the focal point in which microglia respond $(\boldsymbol{F})$, and the velocity of converging processes $(\boldsymbol{G}) ;{ }^{* * *} p<0.001$.

creases to $92 \pm 1.7 \%$ (range, $77-98 \% ; n=10$ slices) in slices and $63.8 \pm 9.1 \%$ (range, $41-87 \% ; n=4$ mice) in vivo, respectively. Comparison of the dynamics of converging processes revealed that the average duration at the convergence point (Fig. 2E) and distance of responding microglia from the focal point (Fig. $2 F$ ) were similar between slices and in vivo. However, in vivo, processes reached the target faster than they did in slices exhibiting twice the process extension velocity (Fig. $2 G$ ). Thus, $\left[\mathrm{Ca}^{2+}\right]_{\mathrm{e}}$ reduction induces MPCs in both brain slices and in vivo.

\section{Microglial process convergence targets neuronal dendrites}

Astrocytes have been proposed to regulate basal microglial motility (Davalos et al., 2005). However, this hypothesis has not been directly tested. To this end, we applied a widely used astrocyte inhibitor, FAC. FAC inhibits astrocytic purinergic responses in hippocampal slices (Pascual et al., 2012). FAC (10 mM) significantly reduced the number of spontaneous calcium transients in hippocampal astrocytes labeled by OGB and SR101 (average $60.8 \pm 7.7 \%$ reduction, $n=6$ slices; Fig. $3 A ; n=10$ representative cells) but failed to alter basal microglial motility when used at concentrations ranging from 1 to $10 \mathrm{~mm}$ (Fig. $3 \mathrm{~B}, \mathrm{C}$ ). Additionally, MPC frequency during nominally calcium-free conditions was unaltered relative to control conditions even after slices were incubated for $90 \mathrm{~min}$ in FAC (Fig. 3D). These results suggest that astrocytic functions are not critical for either basal microglial dynamism or low $\mathrm{Ca}^{2+}$-induced MPCs. Next, dual-cell imaging of microglia and astrocytes evidenced no termination of microglial processes during MPCs on astrocytic elements (0 of 43 events; Fig. 3E-G).

To determine whether microglial processes terminate on neuronal elements, we crossed mice expressing GFP in microglia with mice expressing YFP in a subset of pyramidal neurons and monitored microglial-neuronal dynamics. We observed several converging processes that terminated on labeled neuronal den- drites (Fig. 3 H, I; Movie 2) but not neuronal somata. In addition, through several hours of imaging in the same slice during calcium-reduction conditions (up to $4 \mathrm{~h}$ ), we did not observe repeated convergent foci terminating in the same location. Finally, we asked whether neuronal action potentials are required for MPCs using TTX (1-2 $\mu \mathrm{M})$ which failed to alter MPC frequency [13.83 \pm 2.1 events before and $13.83 \pm 3.7$ events during TTX treatment, $(n=6)]$.

\section{Microglial process convergence is mediated by purines through $\mathrm{P} 2 \mathrm{Y} 12$ receptors}

To test the involvement of purinergic signaling in MPCs, we used pharmacological and genetic approaches. First, we attempted to abolish endogenous purinergic gradients that may occur during calcium depletion. We reasoned that increasing global ambient ATP levels would eliminate localized gradients of ATP increases that may result during calcium reduction. Indeed, bath application of ATP (1 mM) prevented the occurrence of MPCs (Fig. 4A). Interestingly, when ATP was bath applied to slices after the initiation of an MPC event, converging microglial processes were stalled preventing the completion of the event (Fig. 4B).

Next, we complemented our pharmacological approach with a genetic approach using P2Y12 knock-out mice. Microglia in these mice are deficient in ATP-induced chemotaxis (Haynes et al., 2006) and lack responses to neuronal hyperactivities (Eyo et al., 2014). Consistent with our pharmacological results, genetic depletion of the P2Y12 receptor eliminated MPCs during extracellular calcium reduction (Fig. $4 A, C$ ) even though microglial numbers in our imaging field-of-view in layer II/III of the cortex were similar between genotypes (Fig. 4D). Together, these data suggest that neurons release purines, such as ATP, during calcium reduction that elicit MPCs to neuronal dendrites through microglial $\mathrm{P} 2 \mathrm{Y} 12$ receptors. 
A
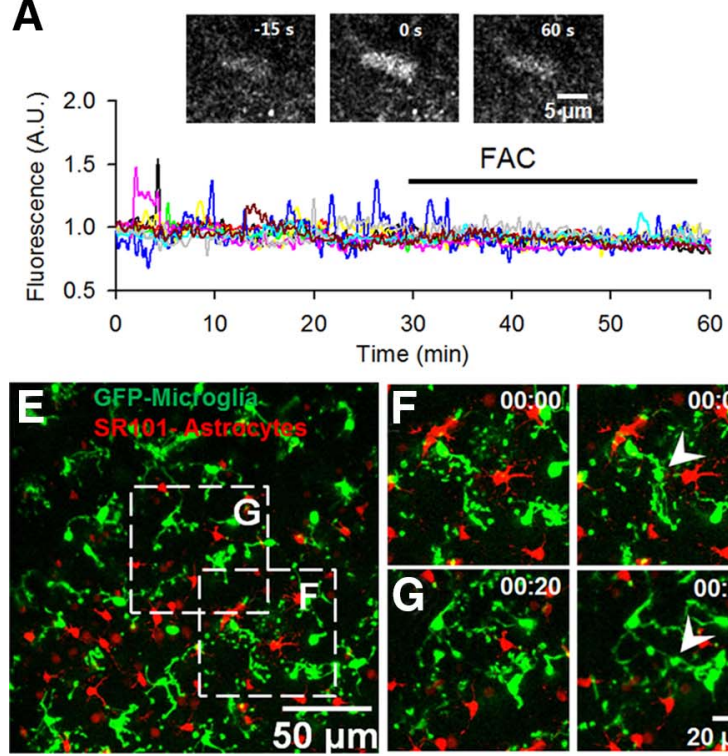

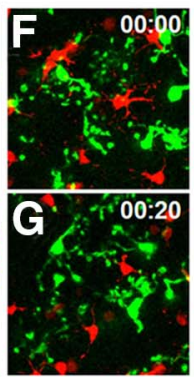

B

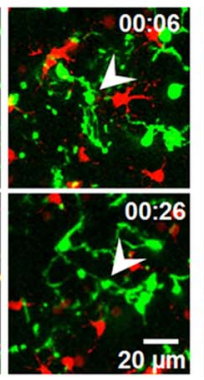

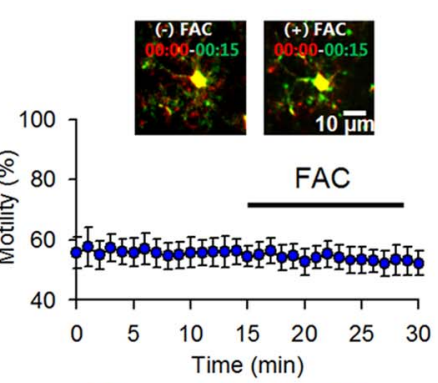

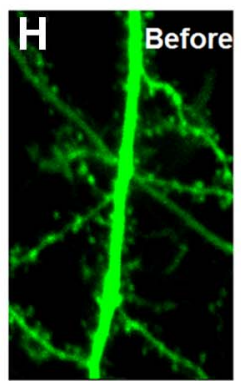

C
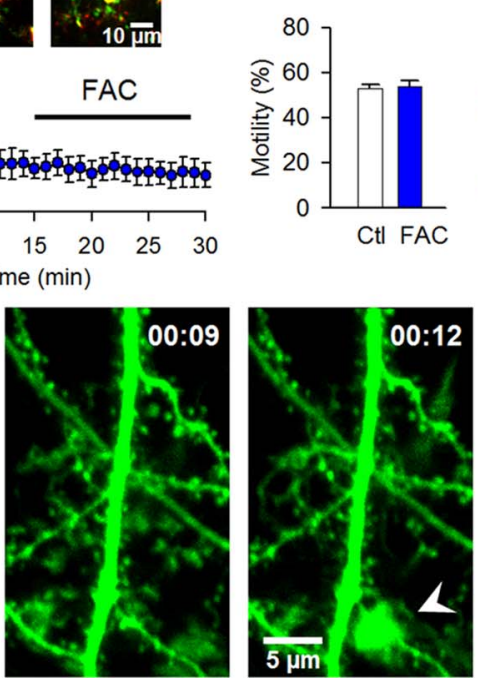

D
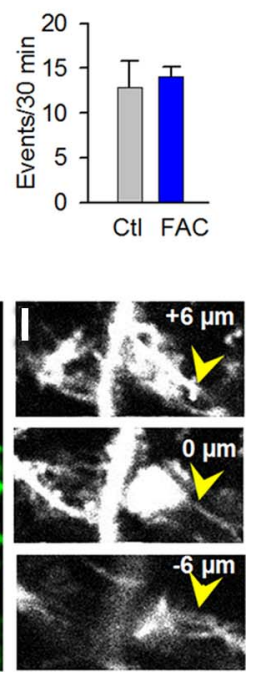

Figure 3. Converging microglial processes target neuronal, but not astrocytic elements. $\boldsymbol{A}$, Spontaneous calcium transients in representative astrocytes in hippocampal slices before and after incubation with $\mathrm{FAC}(10 \mathrm{~mm} ; n=10$ representative cells). Inset, A single astrocyte with a calcium transient in control condition. $\boldsymbol{B}, \boldsymbol{C}$, Representative color-coded images (inset) of microglial dynamics $(\boldsymbol{B}, \boldsymbol{C})$ before (control, $\mathrm{Ct})$ and after incubation with $10 \mathrm{~mm} \mathrm{FAC} \mathrm{(} n=4$ slices). $\boldsymbol{D}$, Quantitative data of microglial process convergence in 1-10 mm FAC ( $n=7$ slices in each condition). $\boldsymbol{E}$, Low-magnification image of GFP-labeled microglia and SR101 stained astrocytes. $\boldsymbol{F}$, $\boldsymbol{G}$, Representative MPCs in boxed region in $\boldsymbol{E}$ with convergence events (white arrowheads). $\boldsymbol{H}$, A representative image of an MPC in a double-transgenic (GFP microglia; YFP neuron) slice showing a process convergence event (white arrowhead) on a neuronal dendrite at high-magnification. I, Single z-stack images at $6 \mu \mathrm{m}$ intervals of $\boldsymbol{H}$. Yellow arrowheads point to the dendrite that is targeted by microglial processes.

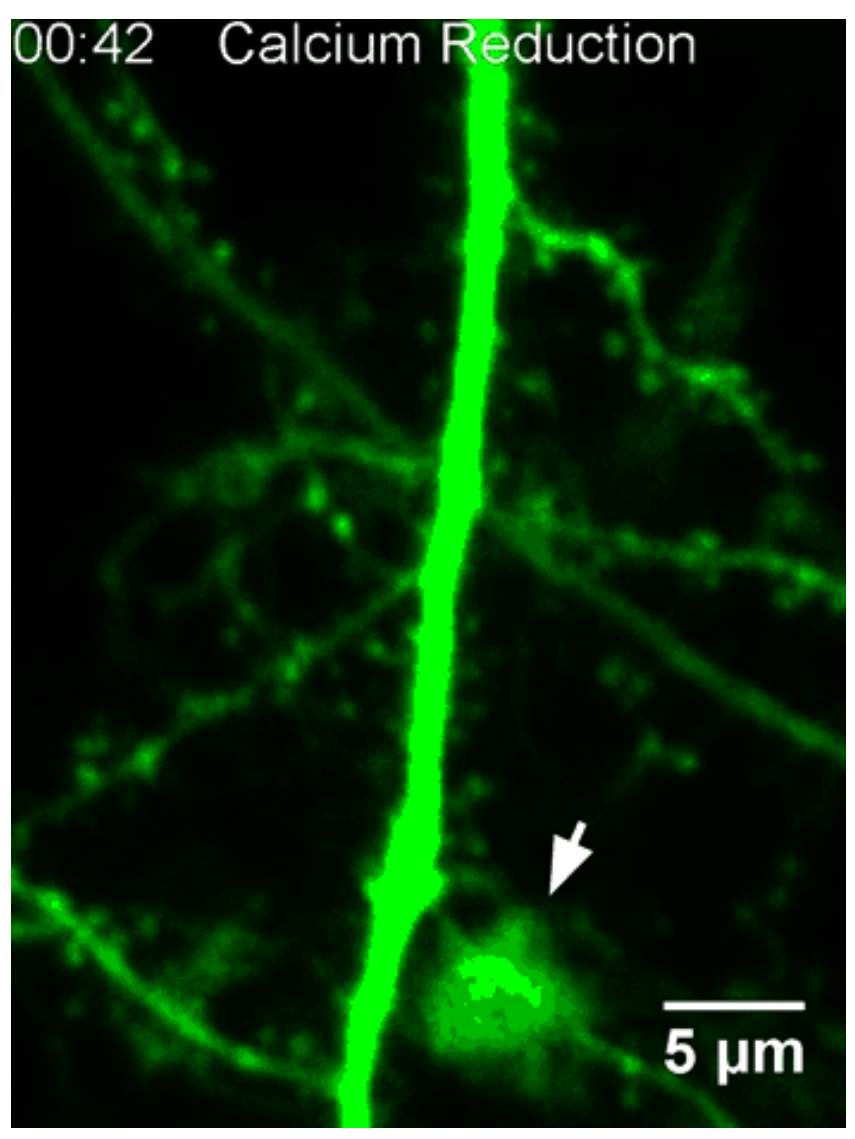

Movie 2. Microglial process convergence terminates on neuronal dendrites. A timelapse movie in a slice with GFP-labeled microglia and YFP-labeled neurons during calcium reduction. $A M P C$ is observed terminating on a labeled dendrite (white arrow). This movie is $30 \mathrm{~min}$ long.
Several pathways are proposed for the release of purines including gap junction channels, hemichannels, and P2X7 receptors (Kang et al., 2008; Thompson and Macvicar, 2008). Interestingly, the occurrence of MPCs remained unchanged in the presence of 10-20 $\mu \mathrm{M} \mathrm{BBG,} \mathrm{a} \mathrm{P2X7} \mathrm{channel} \mathrm{antagonist,} \mathrm{and}$ $50 \mu \mathrm{M}$ CBX, a blocker of connexin channels. However, application of $5 \mathrm{~mm}$ probenecid, a nonselective pannexin-channel inhibitor, significantly reduced the frequency of MPCs (Fig. 4E). Furthermore, the maximum distance of responding microglia from the focal point of convergence during calcium reduction although unchanged during BBG and CBX application, was significantly reduced in the presence of probenecid (Fig. $4 F$ ). Together, these results suggest that ATP is released through probenecid-sensitive channels during extracellular calcium reduction leading to MPCs.

\section{Discussion}

Microglia are morphologically plastic surveillant cells resident in the CNS (Davalos et al., 2005; Nimmerjahn et al., 2005). During their surveillance, they make transient contact with neuronal elements that increase following transient ischemia and neuronal activity (Wake et al., 2009; Tremblay et al., 2010). Moreover, basal microglial dynamics seems to be, at least in part, controlled by ionotropic glutamatergic neurotransmission in the mammalian retina (Fontainhas et al., 2011). Here, we show that neuronal dendrites can trigger MPCs, upon extracellular calcium reduction in brain slices and in vivo through activation of microglial $\mathrm{P} 2 \mathrm{Y} 12$ receptors. These novel findings of microglial-neuronal interactions may be especially relevant during conditions of reduced brain calcium levels as occurs during intense synaptic activity or neural pathology.

Microglial process convergence: a novel form of microglialneuronal interaction

MPCs occur at a low-frequency so it is not surprising that they have not been previously described. We have serendipitously ob- 


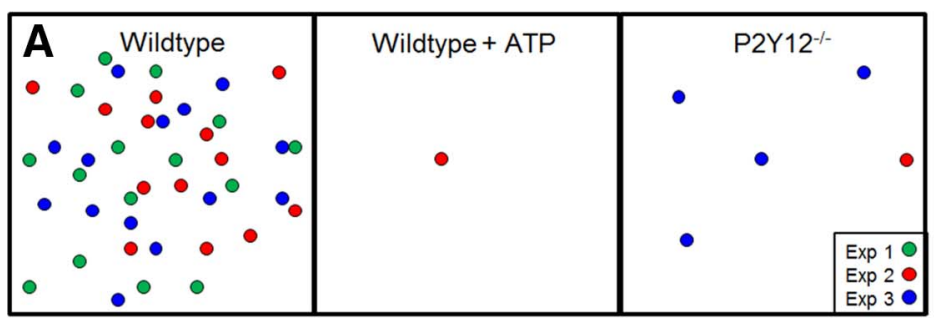

C

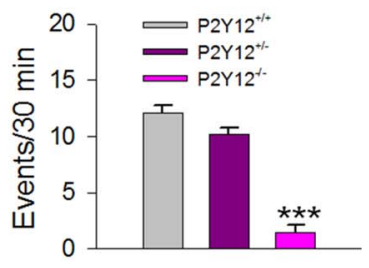

D

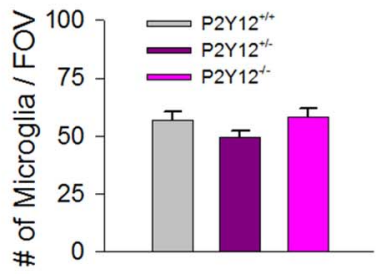

$\mathbf{E}$
B

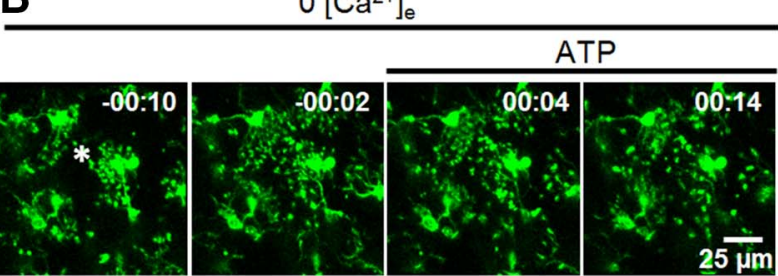

$\mathbf{F}$

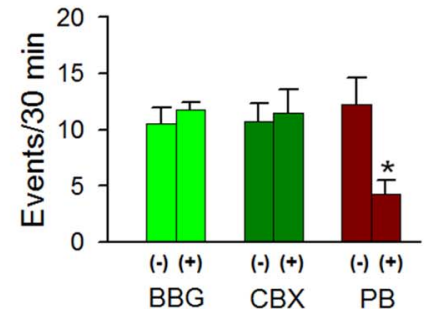

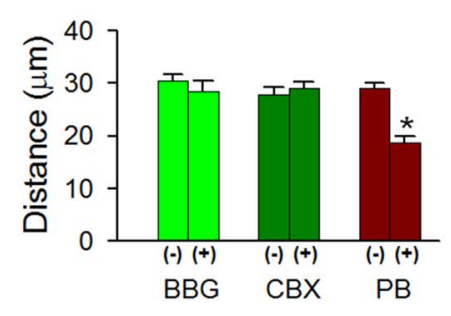

Figure 4. Microglial process convergence requires microglial P2Y12 receptors. $A$, Schematic showing MPCs in the presence of ATP ( $1 \mathrm{~mm} ; n=5$ slices) and in P2Y12 knock-out mouse slices ( $n=$ 8 slices) during calcium reduction. $\boldsymbol{B}$, A sample initiating MPC that fails to be terminated upon application of ATP (asterisk indicates presumptive foci). $\boldsymbol{C}, \boldsymbol{D}, \mathrm{MPC}$ occurrence ( $\boldsymbol{C}$ ) and microglial density (D) in P2Y12 wild-type, heterozygote, and knock-out slices. $E, F$, Quantitative data showing effects of P2X7 antagonists (BBG; $10-20 \mu \mathrm{m} ; n=5$ slices), connexin blocker (CBX, $100 \mu \mathrm{m} ; n=4$ slices), and pannexin channel blocker $(\mathrm{PB}, 5 \mathrm{~mm} ; n=6$ slices $)$ on the occurrence of these events $(\boldsymbol{D})$ and distance of responding microglia from the process convergence focal point $(\boldsymbol{E}) ;{ }^{*} p<0.05$, Student's $t$ test; ${ }^{* * *} p<0.001$, ANOVA.

served them in the cortex, hippocampus, amygdala, and striatum, suggesting that MPCs are a general feature of microglial behaviors in the brain. We found that both in slices and in vivo the kinetics of MPCs was local (microglia responded within $30 \mu \mathrm{m}$ from the focal contact point), rapid (with processes extending at up to $\sim 2-4 \mu \mathrm{m} / \mathrm{min}$ ) and transient (with focal contact lasting $\sim 4 \mathrm{~min}$ ). At present, microglial functions upon focal contact are not clear. However, MPCs could be one of the homeostatic features of microglial activities.

With respect to the target(s) of MPCs, we found that such processes never targeted a microglial element. Astrocytes have been reported to sense extracellular calcium reductions in slices and release ATP (Torres et al., 2012). However, we failed to observe microglial process convergence toward SR101-labeled astrocytic elements. Because SR101 may not label the fine details of elaborate astrocytic processes, we cannot rule out the possibility that some of such processes may be targeted during MPCs especially because astrocytic processes which are sometimes difficult to resolve optically also enwrap neuronal synapses. Future work using GFP labeled astrocytes (Zhuo et al., 1997; Bardehle et al., 2013) could help fully resolve this issue. Consistent with the idea that astrocytes are not MPC targets, blocking astrocytic functions with FAC, a widely used gliotoxin, did not influence MPC occurrence. However, we cannot rule out the possibility that although FAC reduces astrocytic somatic calcium fluxes, astrocytic processes may still release ATP in the presence of FAC.

MPCs were observed to frequently terminate on neuronal dendrites. Because only a small population of neurons are labeled in the transgenic mouse line, we cannot rule out the possibility that unlabeled neuronal somata are targeted by converging processes. However, two observations suggest that dendrites are the primary target. First, in hippocampal slices, we rarely observed MPCs directed toward the stratum pyramidale (SP) where neuronal cell bodies accumulate. Indeed the rare occurrences of such convergence could actually be directed toward dendrites present in the SP. Second, despite extensive imaging throughout our study, we never observed MPCs terminating on a neuronal soma strongly suggesting that dendrites are the predominant (if not the sole) target of MPCs.

Our data from both pharmacological and genetic approaches indicate that purinergic signaling is required for MPCs specifically through microglial P2Y12 receptors. Although microglial P2Y12 receptors have been previously shown to play important roles in microglial chemotaxis to neural injury (Haynes et al., 2006; Eyo et al., 2014), our results provide evidence for a role of purinergic signaling in microglial-neuronal interactions.

\section{Regulation of microglial process convergence}

Our results in slices show that extracellular calcium concentrations as high as $1 \mathrm{~mm}$ are capable of triggering MPCs. Since normal brain extracellular calcium ranges between 1 and $2 \mathrm{~mm}$, it suggests that microglial responses are exquisitely sensitive to decreases in physiological $\left[\mathrm{Ca}^{2+}\right]_{e}$. For simplicity, our experiments were performed in nominally free extracellular calcium conditions. However, to ensure that the phenomena did not result from an imbalance in divalent cation concentrations, we confirmed with other experiments that the phenomena persisted in nominally free calcium conditions with $4 \mathrm{mM} \mathrm{Mg}^{2+}$ (data not shown).

It remains unclear how extracellular calcium reduction triggers MPCs, though several possibilities exist. First, $\left[\mathrm{Ca}^{2+}\right]_{\mathrm{e}}$ reduction is known to increase neuronal excitability (Lu et al., 2010), which may trigger purine release and elicit MPCs. Interestingly, our results indicate that MPCs occur independent of neuronal action potential firing. Second, $\left[\mathrm{Ca}^{2+}\right]_{\mathrm{e}}$ reduction directly activates some ion channels that are able to release chemoattractants, such as ATP (Sabirov and Okada, 2005). A recent study showed that $\left[\mathrm{Ca}^{2+}\right]_{\mathrm{e}}$ could modulate pannexin channel activities including ATP release in calciumfree conditions (Poornima et al., 2012). Indeed, our data suggest that probenecid-sensitive channels but not connexins or the P2X7 receptor may be involved in MPCs. However, high concentrations of the drug were required for MPC inhibition in our study raising the possibility of nonpannexin mechanisms for ATP release, such as neuronal calcium-sensitive channels like CAMHL1 (Taruno et al., 2013) 
and TRP channels (Wei et al., 2007). Thus, the precise neuronal mechanisms that trigger these microglial responses during calcium reduction remain to be determined.

In conclusion, we have uncovered a novel phenomenon of microglial process convergence that is significantly potentiated by extracellular calcium reduction. Our results indicate that during conditions of even slight reductions in extracellular calcium in the brain, microglia sense and contact neuronal dendrites via purinergic signaling. The functional significance of this specific microglia-neuron interaction is an open question. Future studies are underway to ascertain the relevance of these observations during conditions of physiological (e.g., glutamatergic neurotransmission) and pathological (e.g., seizures and ischemia) neuronal activity when extracellular calcium depletion occurs in tissues.

\section{References}

Bardehle S, Krüger M, Buggenthin F, Schwausch J, Ninkovic J, Clevers H, Snippert HJ, Theis FJ, Meyer-Luehmann M, Bechmann I, Dimou L, Götz M (2013) Live imaging of astrocyte responses to acute injury reveals selective juxtavascular proliferation. Nat Neurosci 16:580-586. CrossRef Medline

Berridge MJ, Lipp P, Bootman MD (2000) The versatility and universality of calcium signalling. Nat Rev Mol Cell Biol 1:11-21. CrossRef Medline

Cavazzini M, Bliss T, Emptage N (2005) Ca2+ and synaptic plasticity. Cell Calcium 38:355-367. CrossRef Medline

Clapham DE (2007) Calcium signaling. Cell 131:1047-1058. CrossRef Medline

Davalos D, Grutzendler J, Yang G, Kim JV, Zuo Y, Jung S, Littman DR, Dustin ML, Gan WB (2005) ATP mediates rapid microglial response to local brain injury in vivo. Nat Neurosci 8:752-758. CrossRef Medline

Eyo UB, Wu LJ (2013) Bidirectional microglia-neuron communication in the healthy brain. Neural Plast 2013:456857. CrossRef Medline

Eyo UB, Peng J, Swiatkowski P, Mukherjee A, Bispo A, Wu LJ (2014) Neuronal hyperactivity recruits microglial processes via neuronal NMDA receptors and microglial P2Y12 receptors after status epilepticus. J Neurosci 34:10528-10540. CrossRef Medline

Feng G, Mellor RH, Bernstein M, Keller-Peck C, Nguyen QT, Wallace M, Nerbonne JM, Lichtman JW, Sanes JR (2000) Imaging neuronal subsets in transgenic mice expressing multiple spectral variants of GFP. Neuron 28:41-51. CrossRef Medline

Fontainhas AM, Wang M, Liang KJ, Chen S, Mettu P, Damani M, Fariss RN, Li W, Wong WT (2011) Microglial morphology and dynamic behavior is regulated by ionotropic glutamatergic and GABAergic neurotransmission. PloS One 6:e15973. CrossRef Medline

Haynes SE, Hollopeter G, Yang G, Kurpius D, Dailey ME, Gan WB, Julius D (2006) The P2Y12 receptor regulates microglial activation by extracellular nucleotides. Nat Neurosci 9:1512-1519. CrossRef Medline

Heinemann U, Konnerth A, Pumain R, Wadman WJ (1986) Extracellular calcium and potassium concentration changes in chronic epileptic brain tissue. Adv Neurol 44:641-661. Medline

Ji K, Akgul G, Wollmuth LP, Tsirka SE (2013) Microglia actively regulate the number of functional synapses. PloS One 8:e56293. CrossRef Medline

Jung S, Aliberti J, Graemmel P, Sunshine MJ, Kreutzberg GW, Sher A, Littman DR (2000) Analysis of fractalkine receptor CX(3)CR1 function by targeted deletion and green fluorescent protein reporter gene insertion. Mol Cell Biol 20:4106-4114. CrossRef Medline

Kang J, Kang N, Lovatt D, Torres A, Zhao Z, Lin J, Nedergaard M (2008) Connexin 43 hemichannels are permeable to ATP. J Neurosci 28:47024711. CrossRef Medline

Kristián T, Siesjö BK (1998) Calcium in ischemic cell death. Stroke 29:705718. CrossRef Medline

Li Y, Du XF, Liu CS, Wen ZL, Du JL (2012) Reciprocal regulation between resting microglial dynamics and neuronal activity in vivo. Dev Cell 23: 1189-1202. CrossRef Medline

Lu B, Zhang Q, Wang H, Wang Y, Nakayama M, Ren D (2010) Extracellular calcium controls background current and neuronal excitability via an UNC79-UNC80-NALCN cation channel complex. Neuron 68:488-499. CrossRef Medline

Marín-Teva JL, Dusart I, Colin C, Gervais A, van Rooijen N, Mallat M (2004)
Microglia promote the death of developing Purkinje cells. Neuron 41: 535-547. CrossRef Medline

Nimmerjahn A, Kirchhoff F, Helmchen F (2005) Resting microglial cells are highly dynamic surveillants of brain parenchyma in vivo. Science 308: 1314-1318. CrossRef Medline

Paolicelli RC, Bolasco G, Pagani F, Maggi L, Scianni M, Panzanelli P, Giustetto M, Ferreira TA, Guiducci E, Dumas L, Ragozzino D, Gross CT (2011) Synaptic pruning by microglia is necessary for normal brain development. Science 333:1456-1458. CrossRef Medline

Parkhurst CN, Yang G, Ninan I, Savas JN, Yates JR 3rd, Lafaille JJ, Hempstead BL, Littman DR, Gan WB (2013) Microglia promote learning-dependent synapse formation through brain-derived neurotrophic factor. Cell 155:15961609. CrossRef Medline

Pascual O, Ben Achour S, Rostaing P, Triller A, Bessis A (2012) Microglia activation triggers astrocyte-mediated modulation of excitatory neurotransmission. Proc Natl Acad Sci U S A 109:E197-205. CrossRef Medline

Poornima V, Madhupriya M, Kootar S, Sujatha G, Kumar A, Bera AK (2012) P2X7 receptor-pannexin 1 hemichannel association: effect of extracellular calcium on membrane permeabilization. J Mol Neurosci 46:585-594. CrossRef Medline

Sabirov RZ, Okada Y (2005) ATP release via anion channels. Purinergic Signal 1:311-328. CrossRef Medline

Schafer DP, Lehrman EK, Kautzman AG, Koyama R, Mardinly AR, Yamasaki R, Ransohoff RM, Greenberg ME, Barres BA, Stevens B (2012) Microglia sculpt postnatal neural circuits in an activity and complementdependent manner. Neuron 74:691-705. CrossRef Medline

Taruno A, Vingtdeux V, Ohmoto M, Ma Z, Dvoryanchikov G, Li A, Adrien L, Zhao H, Leung S, Abernethy M, Koppel J, Davies P, Civan MM, Chaudhari N, Matsumoto I, Hellekant G, Tordoff MG, Marambaud P, Foskett JK (2013) CALHM1 ion channel mediates purinergic neurotransmission of sweet, bitter and umami tastes. Nature 495:223-226. CrossRef Medline

Thompson RJ, Macvicar BA (2008) Connexin and pannexin hemichannels of neurons and astrocytes. Channels 2:81-86. CrossRef Medline

Torres A, Wang F, Xu Q, Fujita T, Dobrowolski R, Willecke K, Takano T, Nedergaard M (2012) Extracellular $\mathrm{Ca}(2)(+)$ acts as a mediator of communication from neurons to glia. Sci Signal 5:ra8. CrossRef Medline

Tremblay MÈ, Lowery RL, Majewska AK (2010) Microglial interactions with synapses are modulated by visual experience. PLoS Biol 8:e1000527. CrossRef Medline

Ueno M, Fujita Y, Tanaka T, Nakamura Y, Kikuta J, Ishii M, Yamashita T (2013) Layer V cortical neurons require microglial support for survival during postnatal development. Nat Neurosci 16:543-551. CrossRef Medline

Wake H, Moorhouse AJ, Jinno S, Kohsaka S, Nabekura J (2009) Resting microglia directly monitor the functional state of synapses in vivo and determine the fate of ischemic terminals. J Neurosci 29:3974-3980. CrossRef Medline

Wakselman S, Béchade C, Roumier A, Bernard D, Triller A, Bessis A (2008) Developmental neuronal death in hippocampus requires the microglial CD11b integrin and DAP12 immunoreceptor. J Neurosci 28:8138-8143. CrossRef Medline

Wei WL, Sun HS, Olah ME, Sun X, Czerwinska E, Czerwinski W, Mori Y, Orser BA, Xiong ZG, Jackson MF, Tymianski M, MacDonald JF (2007) TRPM7 channels in hippocampal neurons detect levels of extracellular divalent cations. Proc Natl Acad Sci U S A 104:16323-16328. CrossRef Medline

Wu LJ, Vadakkan KI, Zhuo M (2007) ATP-induced chemotaxis of microglial processes requires $\mathrm{P} 2 \mathrm{Y}$ receptor-activated initiation of outward potassium currents. Glia 55:810-821. CrossRef Medline

Wu LJ, Wu G, Akhavan Sharif MR, Baker A, Jia Y, Fahey FH, Luo HR, Feener EP, Clapham DE (2012) The voltage-gated proton channel Hvl enhances brain damage from ischemic stroke. Nat Neurosci 15:565-573. CrossRef Medline

Zhuo L, Sun B, Zhang CL, Fine A, Chiu SY, Messing A (1997) Live astrocytes visualized by green fluorescent protein in transgenic mice. Dev Biol 187: 36-42. CrossRef Medline

Zorec R, Araque A, Carmignoto G, Haydon PG, Verkhratsky A, Parpura V (2012) Astroglial excitability and gliotransmission: an appraisal of $\mathrm{Ca}^{2+}$ as a signalling route. ASN Neuro 4:e00080. CrossRef Medline 